\title{
Determination of Rhodamine B Pigment in Food Samples by Ionic Liquid Coated Magnetic Core/Shell $\mathrm{Fe}_{3} \mathrm{O}_{4} @ \mathrm{SiO}_{2}$ Nanoparticles Coupled with Fluorescence Spectrophotometry
}

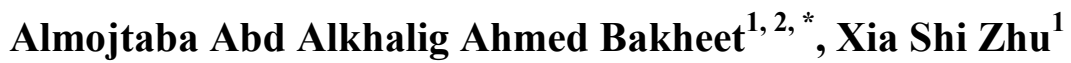 \\ ${ }^{1}$ Department of Analytical Chemistry, College of Chemistry \& Chemical Engineering, Yangzhou University, Yangzhou, China \\ ${ }^{2}$ Department of Family Sciences, Faculty of Education, University of Khartoum, Khartoum, Sudan \\ Email address: \\ m.bakeet@yahoo.com (A. A. A. A. Bakheet), moj76@uofk.edu (A. A. A. A. Bakheet), xszhu@yzu.edu.cn (Xia Shi Zhu) \\ *Corresponding author
}

\section{To cite this article:}

Almojtaba Abd Alkhalig Ahmed Bakheet, Xia Shi Zhu. Determination of Rhodamine B Pigment in Food Samples by Ionic Liquid Coated Magnetic Core/Shell $\mathrm{Fe}_{3} \mathrm{O}_{4} @ \mathrm{SiO}_{2}$ Nanoparticles Coupled with Fluorescence Spectrophotometry. Science Journal of Chemistry.

Vol. 5, No. 1, 2017, pp. 1-7. doi: 10.11648/j.sjc.20170501.11

Received: December 18, 2016; Accepted: January 18, 2017; Published: March 6, 2017

\begin{abstract}
The Ionic liquids (IL) 1-octyl-3-methylimidazole hexafluorophosphate ([OMIM] $\mathrm{PF}_{6}$ ) was selected from three ILs along with (1-butyl-3-methylimidazole hexafluorophosphate ([BMIM]PF6), 1-hexyl-3-methyl-imidazole hexafluoro-phosphate ([HMIM]PF6), were coated by $\mathrm{Fe}_{3} \mathrm{O}_{4} @ \mathrm{SiO}_{2}$ nanoparticles with core-shell structure to prepare magnetic solid phase extraction agent $\left(\mathrm{Fe}_{3} \mathrm{O}_{4} @ \mathrm{SiO}_{2} @ \mathrm{IL}\right)$ and establish a new method of magnetic solid phase extraction (MSPE) coupled with Fluorescence spectrophotometry for separation/analysis of Rhodamine B. The results showed that Rhodamine B was adsorbed rapidly byFe $\mathrm{O}_{4} @ \mathrm{SiO}_{2} @\left[\mathrm{OMIM}_{\mathrm{PF}_{6}}\right.$ and eluted by ethanol. Under the optimal conditions the linear range, detection limit (DL), correlation coefficient (R) and relative standard deviation (RSD) were found to be $0.40-140.00 \mu \mathrm{g} \mathrm{L}^{-1}, 0.06 \mu \mathrm{g} \mathrm{L}^{-1}, 0.9993$ and $0.45 \%\left(\mathrm{n}=3, \mathrm{c}=10.00 \mu \mathrm{g} \mathrm{L}^{-1}\right)$, respectively. The pre-concentration factor of the proposed method was 25-fold. The $\mathrm{Fe}_{3} \mathrm{O}_{4} @ \mathrm{SiO}_{2}$ NPs can be used repeatedly for 10 times. This method has been applied to the determination of Rhodamine B in food samples.
\end{abstract}

Keywords: Rhodamine B, IL-magnetic Nanoparticles, Magnetic SPE, Fluorescence Spectrophotometry

\section{Introduction}

Rhodamine $\mathrm{B}(\mathrm{RhB})$, a red pigment, is widely used as colorant in textiles, dyeing, paper and printing [1]. $\mathrm{RhB}$ is harmful if swallowed by human and animals, and causes irritation to the skin, eyes and respiratory tract "[2], [3], [4]", and has been considered and used as color additive in foodstuffs. Because of the low price and bright color of rhodamine B, some traders use it as a food additive illegally [5], harming the health of consumers [6]. Thus, due to this, it was considered worthwhile to make efforts to develop a simple method for the determination of RhB in different samples. Various techniques have been developed for the determination of $\mathrm{RhB}$ to date, including ultraviolet spectrophotometry [7], fluorescence spectrophotometry [8], capillary chromatography [9], high-performance liquid chromatography (HPLC) [10]. However, direct determination with spectrophotometry is difficult owing to low concentration of $\mathrm{RhB}$ in natural samples. So that, it is important to develop a new method for determination/separation procedure of RhB.

Magnetic solid phase extraction (MSPE) is a technique that uses a magnetic material as absorbent matrix in solidphase extraction technique [11]. In MSPE procedures, the magnetic adsorbents are exposed in the sample solution to adsorb the analyte and then collect the analyte by an external magnetic field, which greatly simplifies the SPE procedure and enhances extraction efficiency [12]. To date, MSPE extraction agent is mainly $\mathrm{Fe}_{3} \mathrm{O}_{4}$ nanoparticles (NPs) with specific chemical functional group modified on the surface to 
achieve concentration of the targeted analyte. Numerous organic polymers and inorganic polymers have been used to modify $\mathrm{Fe}_{3} \mathrm{O}_{4}$ NPs. Gao et al. used polyaniline loaded $\mathrm{Fe}_{3} \mathrm{O}_{4}$ (PANIs $/ \mathrm{Fe}_{3} \mathrm{O}_{4}$ ) as sorbents for magnetic solid-phase extraction fluoroquinolones in honey samples [13]. Cao et al. used ionic liquid coated $\mathrm{Fe}_{3} \mathrm{O}_{4} @$ graphene (IL/ $\mathrm{Fe}_{3} \mathrm{O}_{4} @$ graphene) as sorbents for magnetic solid-phase extraction nitrobenzene compounds in environmental water samples extraction [14]. Liu et al. used magnetic coremesoporous shell microspheres with $\mathrm{C}_{18}$-functionalized interior pore-walls $\left(\mathrm{C}_{18}-\mathrm{Fe}_{3} \mathrm{O}_{4} @ \mathrm{mSiO}_{2}\right)$ as adsorbent measured the residue of cephalosporins in milk [15]. However, it has not been reported for determination of $\mathrm{RhB}$ using $\mathrm{Fe}_{3} \mathrm{O}_{4} @ \mathrm{SiO}_{2} @$ IL.

In the present work, we have prepared magnetic solid phase extraction agents, $\mathrm{Fe}_{3} \mathrm{O}_{4} @ \mathrm{SiO}_{2} @$ ILsthrough selfassembly. This extraction agent combines the advantages of the ILs and the magnetic nanoparticles (MNPs). Compared with the previously reported works "[16], [17], [18]", this adsorbent based MSPE providing a rapid, and efficient sample preparation process, which enables the treatment of large volume samples in a short period of time. A novel MSPE method coupled with Fluorescence spectrophotometry was therefore established for separation/analysis of $\mathrm{RhB}$ from food samples.

\section{Experimental}

\subsection{Equipment and Reagents}

FTIR spectra were measured with a Bruker Tensor 27 spectrometer (Bruker Company, Germany). Samples were pressed into $\mathrm{KBr}$ pellets and recorded at the frequencies from 4000 to $400 \mathrm{~cm}^{-1}$ with resolution of $4 \mathrm{~cm}^{-1}$. A Tecnai 12 TEM (Philips, Netherlands) was used to obtain micrographs of the MNPs. Chromatographic separation of analytes was achieved with Fluorescence spectrophotometry.

All chemicals and reagents were at least of analytical reagent grade, unless otherwise stated. $\mathrm{RhB}$ standards were purchased from Shanghai Chemical Reagent Corporation, (China). A standard stock solution was prepared by dissolving $10.0 \mathrm{mg}$ of each standard in $100 \mathrm{~mL}$ of ethanol and stored in dark at $4^{\circ} \mathrm{C}$. N-methylimidazole (Darui Fine Chemicals, Shanghai, China), N-butyl bromide, 1Bromohexane, 1-Bromooctane, tetraethyl orthosilicate (TEOS), $\mathrm{KPF}_{6}, \mathrm{FeCl}_{3},\left(\mathrm{NH}_{4}\right)_{2} \mathrm{Fe}\left(\mathrm{SO}_{4}\right)_{2}$, methanol, ethanol, acetone, methylene chloride (Sinopharm Chemical Reagent Co., Ltd., Shanghai, China).

\subsection{SynthesisofFe $\mathrm{O}_{3} @ \mathrm{SiO}_{2} @ I L$}

The two-step synthesis A series of ionic liquids 1-alkyl-3methylimidazolium hexafluorophosphate were synthesized using a two-step method described in previous reports "[19], [20], [21], [22]".

$\mathrm{Fe}_{3} \mathrm{O}_{4} \mathrm{MNPswere}$ prepared by chemical co-precipitation "[23], [24]".

For preparation of $\mathrm{Fe}_{3} \mathrm{O}_{4} @ \mathrm{SiO}_{2}$ a previously reported process was followed "[25], [26]".

ILs functionalized MNPs $\left(\mathrm{Fe}_{3} \mathrm{O}_{4} @ \mathrm{SiO}_{2} @[\mathrm{BMIM}] \mathrm{PF}_{6}\right.$, $\mathrm{Fe}_{3} \mathrm{O}_{4} @ \mathrm{SiO}_{2} @[\mathrm{HMIM}] \mathrm{PF}_{6}$ and $\mathrm{Fe}_{3} \mathrm{O}_{4} @ \mathrm{SiO}_{2} @[\mathrm{OMIM}] \mathrm{PF}_{6}$ ) were synthesized following a procedure described the literature [27].

\subsection{MSPE Procedure}

The MSPE procedure was done as follows. First, $\mathrm{Fe}_{3} \mathrm{O}_{4} @ \mathrm{SiO}_{2} @[\mathrm{OMIM}] \mathrm{PF}_{6}$ MNPs were added to a $40 \mathrm{~mL}$ water sample containing $\mathrm{RhB}(\mathrm{pH}=3.0)$, and the mixture was placed on a slow-moving platform shaker and allowed to equilibrate for $10 \mathrm{~min}$ at $30^{\circ} \mathrm{C}$. Then, a strong magnet was applied to the bottom of the beaker, isolating the $\mathrm{Fe}_{3} \mathrm{O}_{4} @ \mathrm{SiO}_{2} @[\mathrm{OMIM}] \mathrm{PF}_{6}$ MNPs from the suspension. After $5 \mathrm{~min}$, the suspension was decanted and the residual solution of $\mathrm{Fe}_{3} \mathrm{O}_{4} @ \mathrm{SiO}_{2} @[\mathrm{OMIM}] \mathrm{PF}_{6} \mathrm{MNPs}$ was transferred to centrifuge tube. The $\mathrm{Fe}_{3} \mathrm{O}_{4} @ \mathrm{SiO}_{2} @[\mathrm{OMIM}] \mathrm{PF}_{6} \mathrm{MNPs}$ were aggregated again by positioning a magnet to the outside of the tube wall so that the residual solution could be completely removed by pipette. Finally, the isolated MNPs were mixed with $3 \mathrm{~mL}$ of ethanol and sonicated for $5 \mathrm{~min}$ to elute the pre-concentrated target analytes. After wards, a magnet was positioned on the outside of the centrifuge tube, and the supernatant solution was collected and F-7000 FL spectrophotometer (Hitachi, Japan) was used for all the fluorescence measurement.

\subsection{Determination Method}

\subsubsection{Extraction}

At room temperature, the sample solution after treatment and the $\mathrm{pH}$ buffer were added into a tube, and then distilled water was added to $40.0 \mathrm{~mL}$. $0.1 \mathrm{~g}$ IL MNPs was added into the tube. The mixture was shaken on the timing multifunctional oscillator for $20.0 \mathrm{~min}$ and then centrifuged. ethanol of $3.0 \mathrm{~mL}$ as elution was added into the used IL MNPs. The mixture was ultrasonically vibrated at room temperature and then centrifuged to obtain supernatant solution. Supernatant solution was determined with fluorescence spectrophotometer.

\subsubsection{Fluorescence Measurements}

In a test tube $(10.0 \mathrm{~mL}), 0.05 \mathrm{~g} 0.01 \mathrm{~mol} / \mathrm{L}$ IL-MNPs, $0.3 \mathrm{~mL}$ of ethanol, $2.0 \mathrm{~mL}$ of buffer solution $(\mathrm{pH}=3.0)$ and adequate Rhodamine B standard solution or sample solution were added; the solution was diluted to the mark with distilled water. Then fluorescence spectra were recorded in the range of 300-700 $\mathrm{nm}$ upon excitation at $570 \mathrm{~nm}$.

\subsection{Sample Preparation}

An amount of $5 \mathrm{~g}$ of chili powder/hot pepper/ Chinese prickly ash were accurately weighed into the beakers respectively, dissolved in $80.0 \mathrm{~mL}$ of ethanol. The resultant clear solution was evaporated to dryness at $60^{\circ} \mathrm{C}$ The residue was diluted with distilled water into a $100.0 \mathrm{~mL}$ flask and stored in darkness for detection. 


\section{Results and Discussion}

\subsection{Characterization of the MNPs}

The synthesized $\mathrm{Fe}_{3} \mathrm{O}_{4} @ \mathrm{SiO}_{2} @$ ILsMNPs were characterized by FT-IR spectroscopy, thermo-gravimetrical analysis and magnetic characterization.

Figure 1. was shown the FTIR spectra of $\mathrm{Fe}_{3} \mathrm{O}_{4}$ (curve a), $\mathrm{Fe}_{3} \mathrm{O}_{4} @ \mathrm{SiO}_{2}$ (curve b), $\mathrm{Fe}_{3} \mathrm{O}_{4} @ \mathrm{SiO}_{2} @[\mathrm{BMIM}] \mathrm{PF}_{6}$ (curve c), $\mathrm{Fe}_{3} \mathrm{O}_{4} @ \mathrm{SiO}_{2} @[\mathrm{HMIM}] \mathrm{PF}_{6} \quad$ (curve d) and $\mathrm{Fe}_{3} \mathrm{O}_{4} @ \mathrm{SiO}_{2} @[\mathrm{OMIM}] \mathrm{PF}_{6}$ (curve e). Compared the curves of $\mathrm{a}$ and $\mathrm{b}$, a peak of $580 \mathrm{~cm}^{-1}$ was assigned to $\mathrm{Fe}-\mathrm{O}-\mathrm{Fe}$ stretching vibration; the strong peaks of $1200-1000 \mathrm{~cm}^{-1}$ correspond to the Si-O-H and Si-O-Si stretching vibration; which indicated that $\mathrm{SiO}_{2}$ had been successfully loaded on the surface of $\mathrm{Fe}_{3} \mathrm{O}_{4}$. In the curve $\mathrm{c}, \mathrm{d}$ and $\mathrm{e}$, the peaks at $2920 \mathrm{~cm}^{-1}$ and $2850 \mathrm{~cm}^{-1}$ corresponded to the $\mathrm{C}-\mathrm{H}$ stretching vibration; the peaks at $1575 \mathrm{~cm}^{-1}$ corresponded to the characteristic absorption of imidazole groups in the $\mathrm{Fe}_{3} \mathrm{O}_{4} @ \mathrm{SiO}_{2} @ \mathrm{ILs}$; in addition, the peak of $840 \mathrm{~cm}^{-1}$ was attributed to the P-F stretching vibration in the $\mathrm{Fe}_{3} \mathrm{O}_{4} @ \mathrm{SiO}_{2} @ \mathrm{ILs}$ [28], which indicated that ILs had been successfully immobilized on the surface of $\mathrm{Fe}_{3} \mathrm{O}_{4} @ \mathrm{SiO}_{2}$.

Thermo-gravimetric analysis (TGA) was conducted in a nitrogen atmosphere, and the heating rate employed was $5^{\circ} \mathrm{C}$ $\mathrm{min}^{-1}$ all cases from 25 to $1000^{\circ} \mathrm{C}$. Figure 2 presents the TGA of $\mathrm{Fe}_{3} \mathrm{O}_{4} @ \mathrm{SiO}_{2}$ and $\mathrm{Fe}_{3} \mathrm{O}_{4} @ \mathrm{SiO}_{2} @[\mathrm{OMIM}] \mathrm{PF}_{6}$. The figure, illustrates a weight loss of $2.7 \%$ at $240^{\circ} \mathrm{C}$ corresponding to the water content. Compared curve a and $\mathrm{b}$, an additional weight loss of $6.6 \%$ is observed from 200 to $650^{\circ} \mathrm{Cwhich}$ is due to the ILs coating.

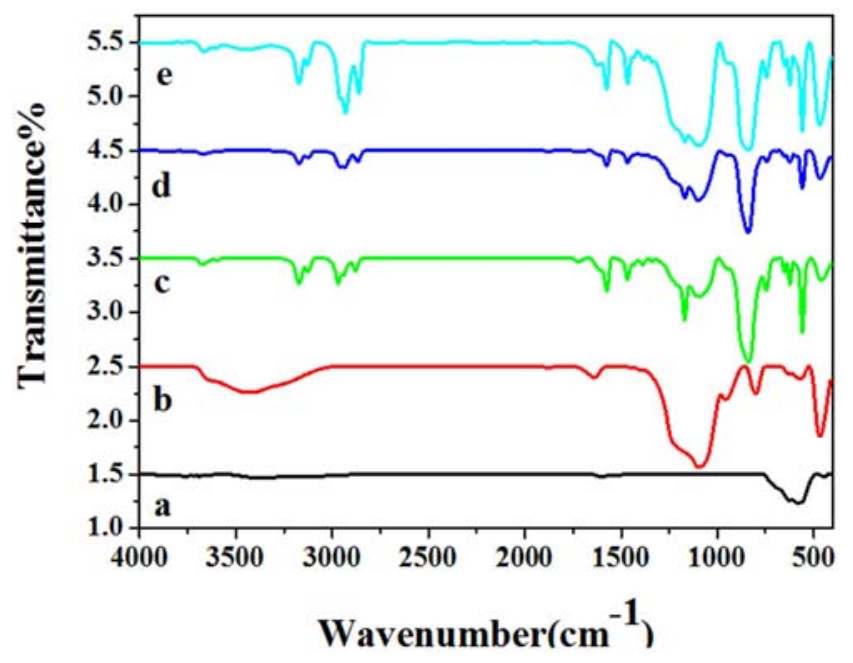

Figure 1. (a) $\mathrm{FTTR}_{\text {spectra of } \mathrm{Fe}_{3} \mathrm{O}_{4}}$ (a), $\mathrm{Fe}_{3} \mathrm{O}_{4} @ \mathrm{SiO}_{2}$ (b), $\mathrm{Fe}_{3} \mathrm{O}_{4} @ \mathrm{SiO}_{2} @\left[\mathrm{BMIM}_{\mathrm{P}} \mathrm{PF}_{6} \quad\right.$ (c), $\mathrm{Fe}_{3} \mathrm{O}_{4} @ \mathrm{SiO}_{2} @[\mathrm{HMIM}] \mathrm{PF}_{6} \quad$ (d) and $\mathrm{Fe}_{3} \mathrm{O}_{4} @ \mathrm{SiO}_{2} @\left[\mathrm{OMIM}_{\mathrm{P}} \mathrm{PF}_{6}(\mathrm{e})\right.$.

* 1-octyl-3-methylimidazolehexafluorophosphate ([OMIM]PF $)$ ), (1-butyl-3methylimidazole hexafluorophosphate ([BMIM]PF6),1-hexyl-3-methylimidazole hexafluoro-phosphate ([HMIM]PF6)

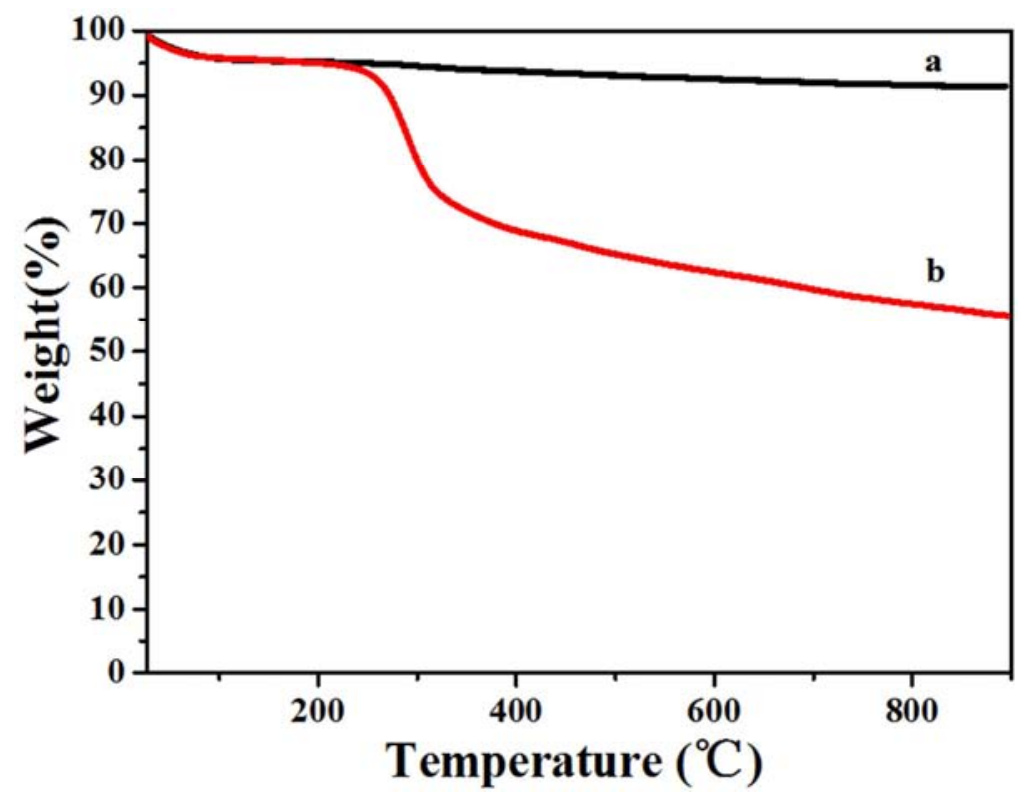

Figure 2.TGA curves of $\mathrm{Fe}_{3} \mathrm{O}_{4} @ \mathrm{SiO}_{2}$ a) and $\mathrm{Fe}_{3} \mathrm{O}_{4} @ \mathrm{SiO}_{2} @ I L(b)$.

\subsection{Optimization of Adsorption}

The factors affecting the adsorption process of $\mathrm{RhB}$ such as $\mathrm{pH}$, temperature and solution volume were studied and the adsorption behavior of $\mathrm{Fe}_{3} \mathrm{O}_{4} @ \mathrm{SiO}_{2} @ \mathrm{PIL}$ on RhB was compared with that of MNPs.

\subsubsection{Effect of $\mathrm{pH}$}

As shown in Figure 3, the adsorption efficiency of RhB was varied with the $\mathrm{pH}$, which was between 3.0 to 12 . It could be concluded that the adsorption (retention) efficiency of RhB on IL MNPs was above $90.0 \%$. It reached the highest value $94.44 \%$ when $\mathrm{pH}$ was 3.0 . As the dissociation constant (pKa) of $\mathrm{RhB}$ is 3.2 , the major existence form of $\mathrm{RhB}$ was molecule form at $\mathrm{pH} 3.0$, the hydrophobicity of molecule form was stronger than its ionic form, Therefore, $\mathrm{pH} 3.0$ was selected for the subsequent assays. 


\subsubsection{Effect of Adsorption Temperature and Time}

The adsorption efficiency of RhB on IL MNPs and MNPs at different temperatures $\left(5.0-60^{\circ} \mathrm{C}\right)$ were studied (Figure 4). The adsorption efficiency of $\mathrm{RhB}$ on $\mathrm{Fe}_{3} \mathrm{O}_{4} @ \mathrm{SiO}_{2} @ \mathrm{IL}$ was higher than that on MNPs and was always above $70 \%$ from $0.5^{\circ} \mathrm{C}$ to $15 .{ }^{\circ} \mathrm{C}$ and was above $85 \%$ from $0.20^{\circ} \mathrm{C}$ to $50 .{ }^{\circ} \mathrm{C}$. The experiment was carried out at room temperature.

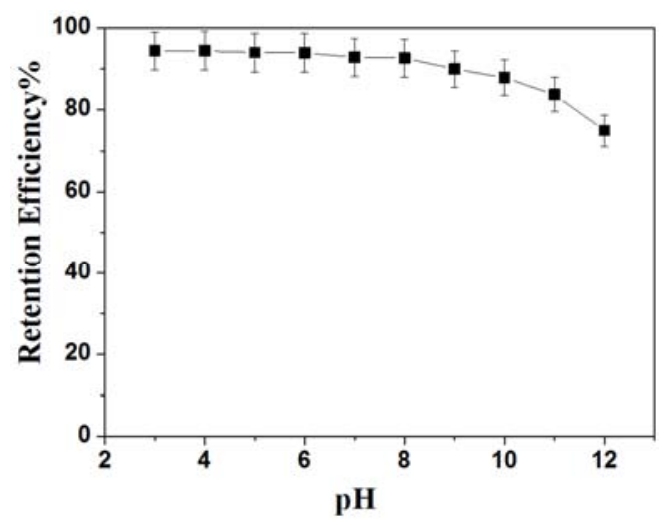

Figure 3. Effect of $p H$ on extraction efficiency $\left(c_{c 0}=10 \mu \mathrm{g} \mathrm{mL}^{-1}\right)$.

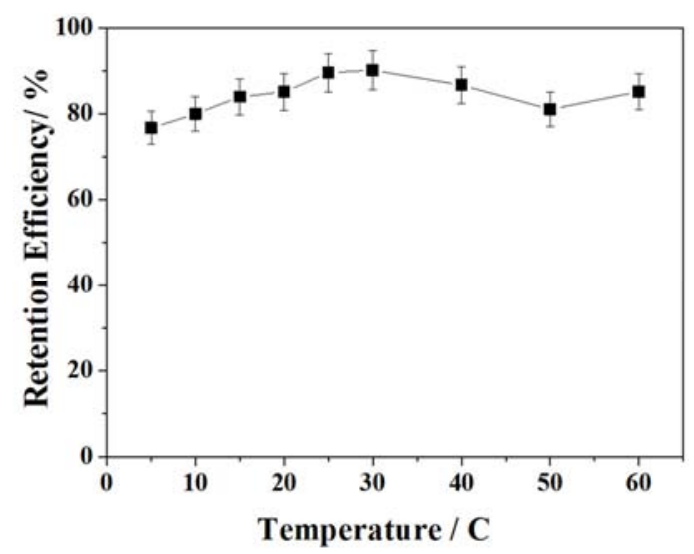

Figure 4. Effect of temperature on extraction efficiency $\left(c_{c 0}=10 \mu \mathrm{gL}^{-1}\right)$.

Effect of adsorption time on extraction efficiency shows the extraction process was completed within $15.0 \mathrm{~min}$, and the adsorption efficiency remained almost stable (86.0\%). 15.0 min as the adsorption time for RhB was adopted (Figure 5).

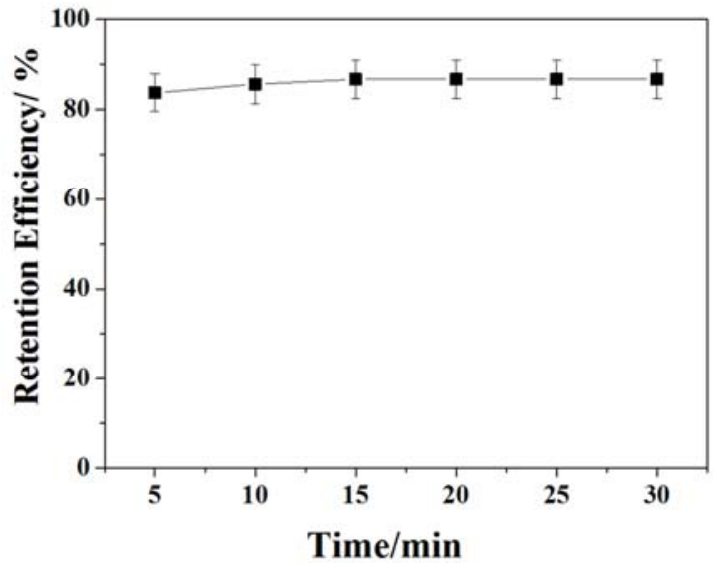

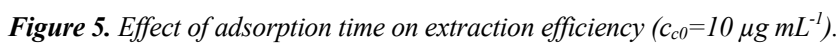

\subsubsection{Effect of the Sample Volume}

The adsorption efficiency of $\mathrm{RhB}$ varied with the increase of sample volume. The amount of RhB was fixed at $50.0 \mu \mathrm{g}$ and the volume of the sample solution increased from 10.0 $\mathrm{mL}$ to $90.0 \mathrm{~mL}$. The adsorption efficiency of $\mathrm{RhB}$ was above $89 \%$ from 10.0 to $80.0 \mathrm{~mL}$ and remain steady. and $77.85 \%$ when sample volume was $90.0 \mathrm{~mL}$. So the largest sample volume allowed was $80.0 \mathrm{~mL}$ (Figure 6).

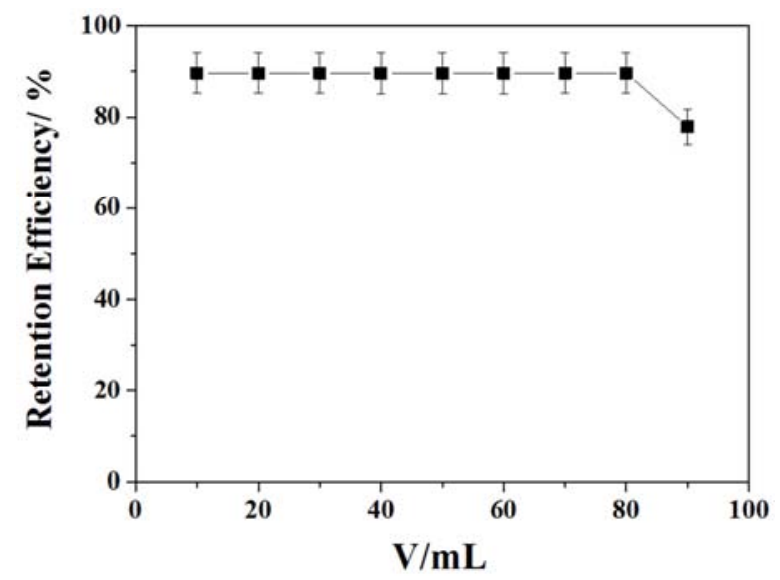

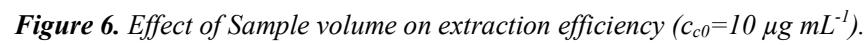

\subsection{Adsorption Capacity}

The adsorption capacity is defined as the maximum amount of $\mathrm{RhB}$ adsorbed per gram of IL MNPs. The adsorption capacity of RhB on IL MNPs was studied (Figure 7). When the concentration of $\mathrm{RhB}$ was $50.0 \mu \mathrm{g} / \mathrm{mL}$ (volume: $50 \mathrm{~mL}$ ), the adsorption of RhB for $0.0225 \mathrm{~g}$ IL MNPs reached the maximum. The adsorption capacity for IL MNPs was calculated as $105.80 \mathrm{mg} / \mathrm{g}$.

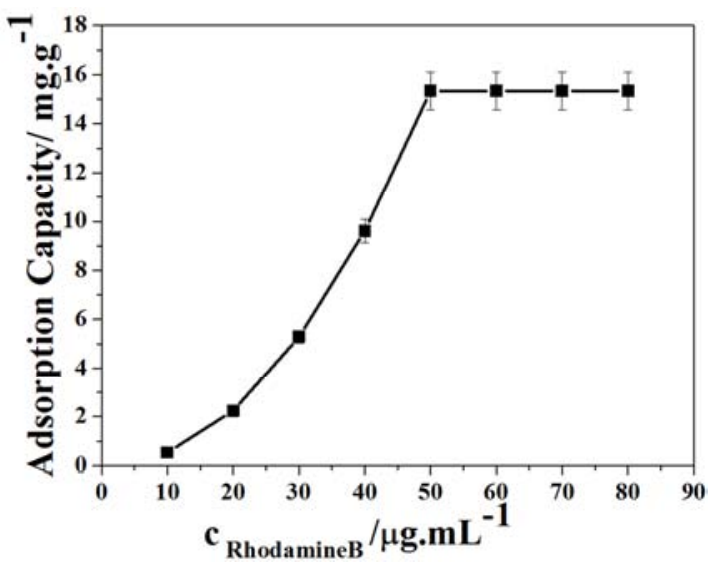

Figure 7. Adsorption capacity.

\subsection{Optimization of Elution}

\subsubsection{Selection of Eluent}

In this work, different eluents were investigated. The order of elution efficiency was ethanol $>$ methanol $>$ cetyltrimethyl ammonium bromide $(\mathrm{CTAB})>$ sodium dodecyl sulfonate $(\mathrm{SDS})>\mathrm{NaOH}(0.1 \mathrm{M})>\mathrm{HCl}(0.1 \mathrm{M})$. So ethanol was adopted as the eluent. Figure 8. 


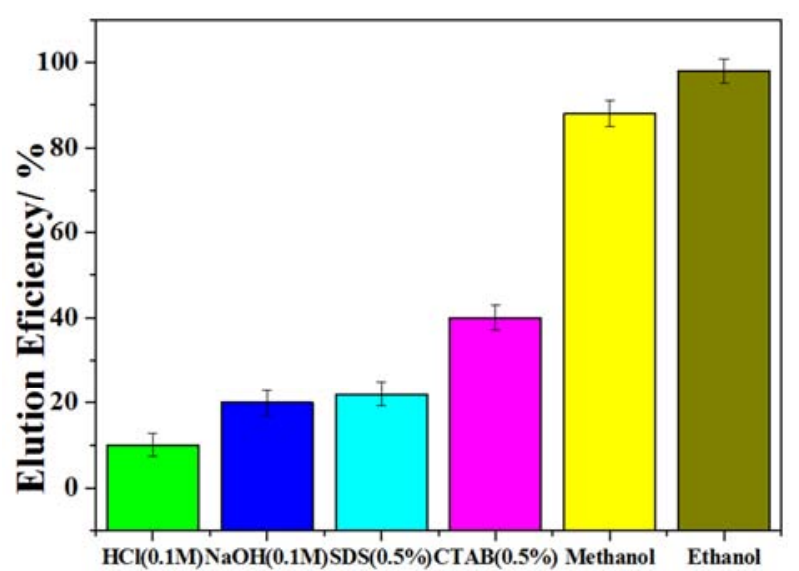

Figure 8. Effect of different dissolvent on elution efficiency.

\subsubsection{Eluent Volume}

The effect of ethanol volume was evaluated on the elution of $\mathrm{RhB}$. The results in Figure 9 described that quantitative elution (above 90\%) was observed as the volume of ethanol was higher than $3.0 \mathrm{~mL}$. The pre-concentration factor is 25 fold. The optimum volume of ethanol was chosen at $3.0 \mathrm{~mL}$.

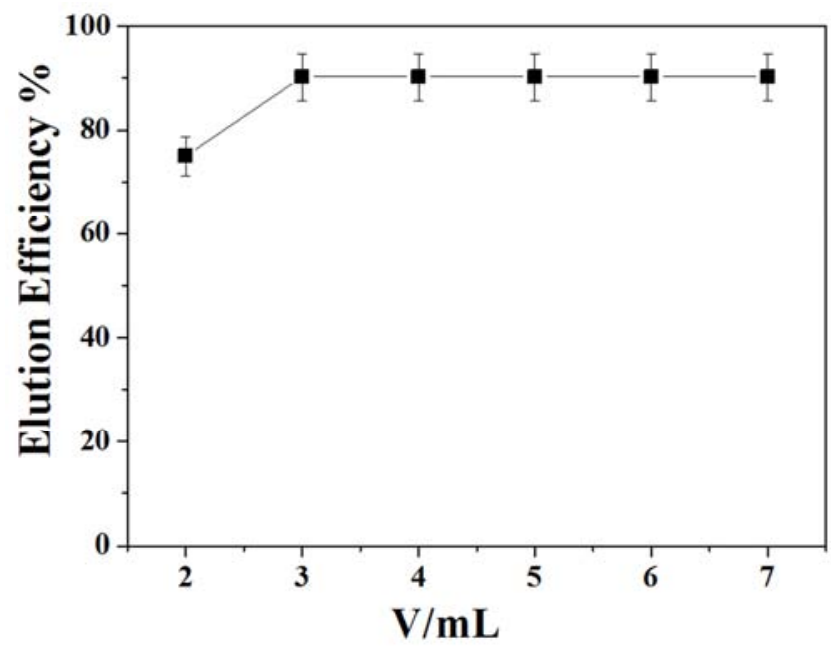

Figure 9. Effect of elution volume on the elution efficiency.

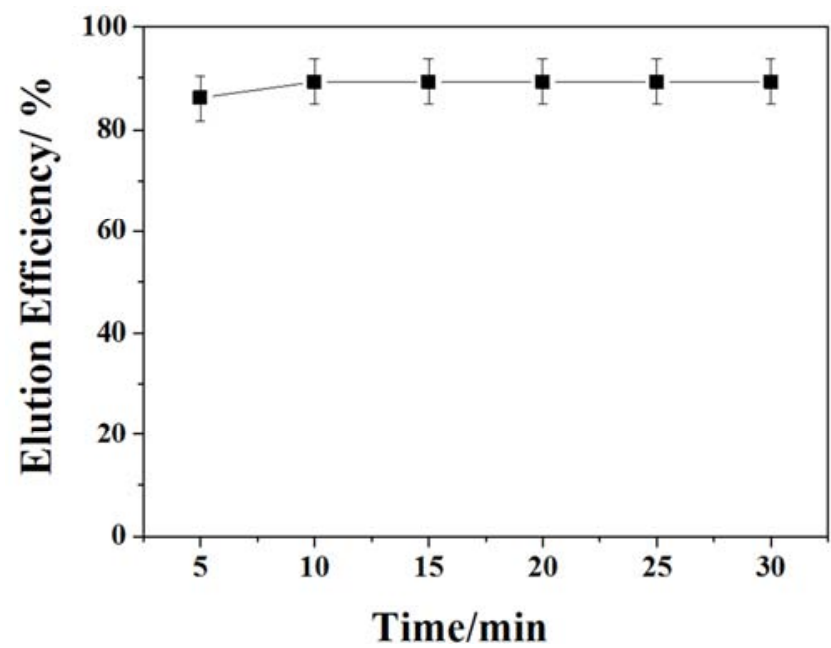

Figure 10. Effect of elution time on elution efficiency.

\subsubsection{Elution Time}

The elution process was completed within $10.0 \mathrm{~min}$, and the elution efficiency did not change with a stable elution efficiency of $89.29 \%$ thereafter. The elution time of $10.0 \mathrm{~min}$ for $\mathrm{RhB}$ was adopted (Figure 10)

\subsection{The Reusability of $\mathrm{Fe}_{3} \mathrm{O}_{4} @ \mathrm{SiO}_{2} @ I L$}

In order to investigate the recycling of the $\mathrm{Fe}_{3} \mathrm{O}_{4} @ \mathrm{SiO}_{2} \mathrm{NPs}$, they were washed with $2 \mathrm{~mL}$ ethanol for twice after each MSPE run, and subsequently assembled with IL. Each re-prepared adsorbent was used for MSPE. The experimental results are shown in Figure 11. It was clear that no obvious loss of the adsorption capacity occurred after ten times of recycling.

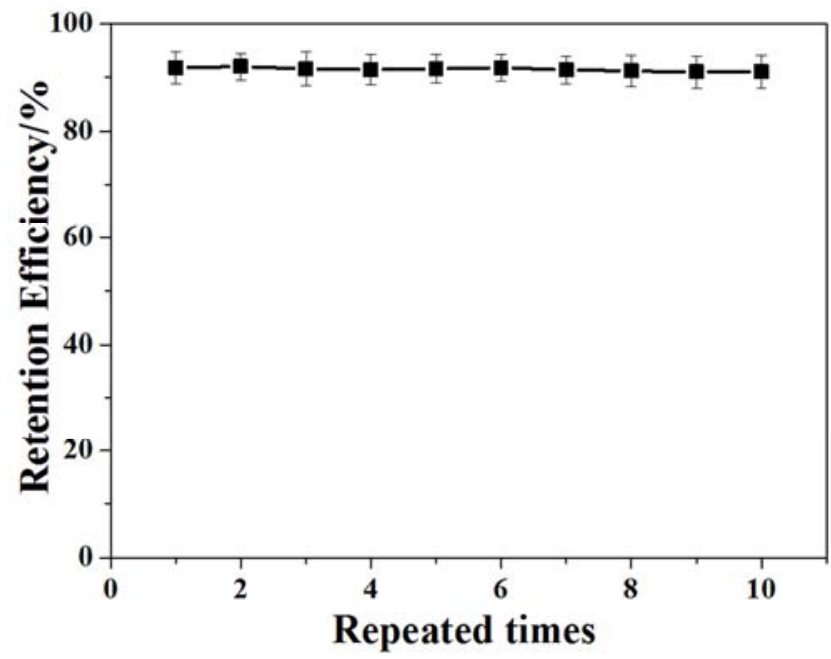

Figure 11. Effect of reuse of IL MNPs in extraction and elution.

\subsection{Evaluation of Interferents}

With a relative error of less than $\pm 5 \%$, the influence of some interferents that food samples contain on the determination of $\mathrm{RhB}$ in the presence of foreign substances was investigated. the tolerance limit for various foreign substances is in table 1 . The results indicated that the majority of these substances in samples had no remarkable interference on the $(\mathrm{RhB})$ determination.

Table 1. Tolerance of interfering substances.

\begin{tabular}{ll}
\hline Interferent & Tolerance ratio \\
\hline $\mathrm{SO}^{2-}, \mathrm{Br}^{-}$ & 400 \\
Citrate, glucose & 230 \\
$\mathrm{NO}^{-}$ & 90 \\
$\mathrm{Zn}^{2+}, \mathrm{Cu}^{2+}$, phenol & 18 \\
Safranin, Bright yellow, Sunset Yellow & 17 \\
Allura Red, Congo red & 8 \\
Rhodamine 6G & 2 \\
\hline
\end{tabular}

\subsection{Analytical Performance of the Method}

Under the optimum conditions, the linear calibration curve was obtained in the concentration range of $0.40-140.00 \mu \mathrm{g} \mathrm{L}^{-1}$. The equations of calibration graph is I (peak area) = 
$11.97 \mathrm{c}+12.11\left(\mu \mathrm{g} \mathrm{L}^{-1}\right)$, with a correlation coefficient of 0.9993 . The limit of detection (DL) was $0.06 \mu \mathrm{g} \mathrm{L}^{-1}$. The relative standard deviation was $0.45 \%\left(\mathrm{n}=3, \mathrm{c}=10.00 \mu \mathrm{g} \mathrm{L}^{-1}\right)$. The preconcentration factor, defined as the quotient of volume before absorption and after elution, is 25 -fold.

\subsection{Sample Analysis}

The proposed method was applied to determine $\mathrm{RhB}$ in chili powder, hot pepper and Chinese prickly ash. RhB is $5.46 \mu \mathrm{g} \mathrm{kg}^{-1}$ in chili powder, with a recovery rate of $\mathrm{RhB}$ of $97.0 \%$ to $103.5 \%$. and it was $4.53 \mu \mathrm{g} \mathrm{kg}^{-1}$ in hot powder with a recovery rate of $\mathrm{RhB}$ of $98.0 \%$.

No $\mathrm{RhB}$ is detected in Chinese prickly ash, the recovery rate of $\mathrm{RhB}$ was from $100.7 \%$ to $100.1 \%$.

Table 2. Determination results of the samples.

\begin{tabular}{llll}
\hline Sample & Added $\left(\mu \mathbf{~ k g}^{-1}\right)$ & Found $\left(\mu \mathbf{~ k g}^{-1}\right)$ & Recovery $(\%)$ \\
\hline & 0 & 5.46 & - \\
Chili powder & 6.00 & 5.01 & 103.5 \\
& 60.00 & 49.50 & 97.0 \\
& 102.00 & 100.9 & 101.8 \\
Hot pepper & 0 & 4.53 & - \\
& 50.00 & 4.03 & 98.0 \\
& 102.0 & 100.5 & 100.7 \\
Chinese & 0 & ND & - \\
prickly ash & 6.00 & 5.02 & 100.7 \\
& 60.00 & 50.4 & 100.8 \\
\hline
\end{tabular}

\subsection{Comparison of the Proposed Method with Relevant Literature}

The comparison of current work with some other methods on the determination of $\mathrm{RhB}$ (Table 2) reveals that this method is either comparable or has rather pronounced advantages over them. Moreover, it is obvious that the present work has high sensitivity, wide linear range, and easy operation.

Table 3 listed the linear range and the limit of detection for the analysis of RhB in real samples obtained by the reported methods, such as solid phase extraction coupled with UV spectrophotometry, solid phase extraction coupled with high performance liquid chromatography, and HPLC-CL method. Compared with other reported methods, the method adopted in the present work obviously had a satisfactory linear range and limit of detection.

Table 3. Comparison with the results in other literatures

\begin{tabular}{lllll}
\hline Method & LR $(\mu \mathbf{g} / \mathbf{L})$ & $\begin{array}{l}\text { LOD } \\
(\mu \mathbf{g} / \mathbf{L})\end{array}$ & $\begin{array}{l}\text { RSD } \\
(\%)\end{array}$ & Ref \\
\hline SPE-UV & - & 3.14 & 5.0 & {$[30]$} \\
SPE-HPLC & $1000-10,000$ & 250 & 2.87 & {$[31]$} \\
HPLC-CL & $1.5-82.1$ & 1.50 & 4.0 & {$[32]$} \\
MSPE-Fluorescence & $0.40-140.00$ & 0.06 & 0.45 & This method \\
\hline
\end{tabular}

\section{Conclusion}

In this work, IL MNPs was synthesized as magnetic solid phase extraction adsorbent to pre-concentrate/separate RhB from real samples. In summary, we have prepared $\mathrm{Fe}_{3} \mathrm{O}_{4} @ \mathrm{SiO}_{2} @ \mathrm{IL}$ as adsorbent, for MSPE of. The magnetic nano-adsorbent is prepared by a self-assembly technique, which is very simple and mild. Compared with traditional SPE, this MSPE based on the $\mathrm{Fe}_{3} \mathrm{O}_{4} @ \mathrm{SiO}_{2} @$ IL MNPs as an SPE adsorbent is fast, and the adsorbent can be easily separated from the sample solution. Moreover, this adsorbent has a high extraction capacity and high enrichment factors and is able to treat large-volume samples in a short period of time. The hydrocarbon chains of ILs on the surface of the adsorbent can provide adsorption sites for Rhodamine $B$ other organic pollutants through $\pi-\pi$ and hydrophobic interactions. The proposed method for the analysis of Rhodamine B is satisfactory. Thus, this adsorbent may also find potential application in the extraction and analysis of other analytes.

\section{Acknowledgements}

The authors acknowledge the financial support from the National Natural Science Foundation of China (21375117) and a project funded by the Priority Academic Program Development of Jiangsu Higher Education Institutions.

\section{References}

[1] Alesso, M., Bondioli, G., Talio, M. C., Luconi, M. O.,\& Fernandez, L. P. (2012). Micelles mediated separation fluorimetric methodology for Rhodamine B determination in condiments, snacks and candies. Food Chemistry, 134, 513517.

[2] Roberts, A. L. K., Fletcher, J. M., Moore, L., \& Byers, S. (2010). Trans-generational exposure to low levels of rhodamine B does not adversely affect litter size or liver function in murine mucopolysaccharidosis type IIIA. Molecular Genetics and Metabolism, 101, 208-213.

[3] Xie, C., Chang, J., Hao, X. D., Yu, J. M., Liu, H. R., \& Sun, X. (2013). Mitochondrial-targeted prodrug cancer therapy using a rhodamine B labeled fluorinated docetaxel. European Journal of Pharmaceutics and Biopharmaceutics, 85, 541-549.

[4] Xiao, J., Gong, S., \& Ledoux, M. S. (2007). Caytaxin deficiency disrupts signaling pathways in cerebellar cortex. Journal of Neuroscience, 144, 439-461.

[5] Jain, R., Mathur, M., Sikarwar, S., \& Mittal, A. (2007). Removal of the hazardous dye rhodamine B through photocatalytic and adsorption treatments. Journal of Environmental Management, 85, 956-964.

[6] Baldev, E., MubarakAli, D., Ilavarasi, A., Pandiaraj, D., Sheik Syed Ishack, K. A., \& Thajuddin, N. (2013). Degradation of synthetic dye, Rhodamine B to environmentally non-toxic products using microalgae. Colloids and Surfaces B: Biointerfaces, 105, 207-214.

[7] Sun, W. J., Li, J., Mele, G., Zhang, Z. Q., \& Zhang, F. X. (2013). Enhanced photocatalytic degradation of rhodamine B by surface modification of $\mathrm{ZnO}$ with copper (II) porphyrin under both UV-vis and visible light irradiation. Journal of Molecular Catalysis A: Chemical, 366, 84-91. 
[8] Chauhan, V. M., Hopper, R. H., Ali, S. Z., King, E. M., Udrea, F., Oxley, C. H., \& Aylott, J. W. (2014). Thermo-optical characterization of fluorescent rhodamine $\mathrm{B}$ based temperature-sensitive nanosensors using a CMOS MEMS micro-hotplate. Sensors and Actuators B, 192, 126-133.

[9] Desiderio, C., Marra, C., \& Fanali, D. S. (1998). Quantitative analysis of synthetic dyes in lipstick by micellar electrokinetic capillary chromatography. Electrophoresis, 19, 1478-1483.

[10] Valverde, R. S., Perez, I. S., Franceschelli, F., Galera, M. M., \& Gil Garcia, M. D. (2007). Determination of photoirradiated tetracyclines in water by high-performance liquid chromatography with chemiluminescence detection based reaction of Rhodamine $B$ with cerium (IV). Journal of Chromatography A, 1167, 85-94.

[11] Ibarra, I. S., Miranda, J. M., Rodriguez, J. A., Nebot, C., \& Cepeda, A. (2014). Magnetic solid phase extraction followed by high-performance liquid chromatography for the determination of sulphonamides in milk samples. Food Chemistry, 157, 511-517.

[12] Jiang, H. M., Yang, T., Wang, Y. H., Lian, H. Z., \& Hu, X. (2013). Magnetic solid-phase extraction combined with graphite furnace atomic absorption spectrometry for speciation of $\mathrm{Cr}$ (III) and $\mathrm{Cr}$ (VI) in environmental waters. Talanta, 116, 361-367.

[13] Gao, Q., Zheng, H. B., Luo, D., Ding, J., \& Feng, Y. Q. (2012). Facile synthesis of magnetic one-dimensional polyaniline and its application in magnetic solid phase extraction for fluoroquinolones in honey samples. Analytica Chimica Acta, 720, 57-62.

[14] Cao, X. J., Shen, L. X., Ye, X. M., Zhang, F. F., Chen, J. Y., \& Mo, W. M. (2014). Ultrasound-assisted magnetic solidphase extraction based ionic liquid-coated $\mathrm{Fe}_{3} \mathrm{O}_{4} @$ graphene for the determination of nitrobenzene compounds in environmental water samples. Analyst, 10, 1-8.

[15] Liu, X. D., Yu, Y. J., Zhao, M. Y., Zhang, H. Y., Li, Y., \& Duan, G. L. (2014). Solid phase extraction using magnetic core mesoporous shell microspheres with $\mathrm{C}_{18}$-modified interior pore-walls for residue analysis of cephalosporins in milk by LC-MS/MS. Food Chemistry, 150, 206-212.

[16] Dzyuba, S. V., \& Bartsch, R. A. (2001). Efficient synthesis of 1-alkyl (aralkyl)-3-methyl (ethyl) imidazolium halids: precursors for room-temperature ionic liquids. Journal of Heterocyclic Chemistry, 38, 265-268.

[17] Chun, S., Dzyuba, S. V., \& Bartsch, R. A. (2001). Influence of structural variation in room-temperature ionic liquids on the selectivity and efficiency of competitive alkai metal salt extraction by a crown ether. Analytical Chemistry, 73, 37373741 .

[18] Holbrey, J. D., \& Seddon, K. R. (1999). The phase behaviour of 1-alky-1 3-methylimidazolium tetrafluoroborates; ionic liquid and ionic liquid crystals. Jurnal of the Chemical Society-Dalton Transactions, 13, 2133-2139.

[19] Tokuda, H., Hayamizu, K., Ishii, K., Susan, M. A. B. H., Tsuzuki, S., Hayamizu, K., \& Watanabe, M. (2004). Physicochemical properties and structures of room temperature ionic liquids. 1. variation of anionic species. The Journal of Physical Chemistry B, 108, 16593-16600.

[20] Huang, R. X., Fang, Z. Q., Yan, X. M., \& Cheng, W. (2012). Heterogeneous sono-Fenton catalytic degradation of bisphenol
A by $\mathrm{Fe}_{3} \mathrm{O}_{4}$ magnetic nanoparticles under neutral condition. Chemical Engineering Journal, 197, 242-249.

[21] Hong, R. Y., Zhang, S. Z., Han, Y. P., Li, H. Z., Ding, J., \& Zheng, Y. (2006). Preparation, characterization and application of bilayer surfactant-stabilized ferrofluids. Powder Technology, 170, 1-11.

[22] Hou, Y. H., Han, X. Y., Chen, J., Li, Z. L., Chen, X. C., \& Gai, L. G. (2013). Isolation of PCR-ready genomic DNA from Aspergillus niger cells with $\mathrm{Fe}_{3} \mathrm{O}_{4} / \mathrm{SiO}_{2}$ microspheres. Separation and Purification Technology, 116, 101-106.

[23] Hu, C. H., Deng, J., Wang, J., Zhao, Y. B., Xia, L. S., Huang, K. H., Ju, S. Q., \& Xiao, N. (2014). A novel core-shell magnetic nano-sorbent with surface molecularly imprinted polymer coating for the selective solid phase extraction of dimetridazole. Food Chemistry, 158, 366-373.

[24] Dang, G. F., Ma, X. G., \& Zhou, J. P. (2012). Preparation of Silica-coated Magnetic Nanomaterials Modified with ionic liquid and its application in detection of trace cadmium ion in water. China Journal of Instrumental Analysis, 7, 823-827.

[25] Cano, F. G., Alcudia-Leon, M. C., Lucena, R., Cardenas, S., \& Valcarcel, M. (2013). Ionic liquid coated magnetic nanoparticles for the gaschromatography/mass spectrometric determination of polycyclicaromatic hydrocarbons in waters. Journal of Chromatography A, 1300, 134-140.

[26] Deng, N., Li, M., Zhao, L. J., Lu, C. F., Rooy, S. L., \& Warner, I. M. (2011). Highly efficient extraction of phenolic compounds by use of magnetic room temperature ionic liquids for environmental remediation. Journal of Hazardous Materials, 192, 1350-1357.

[27] Liu, X. F., Lu, X., Huang, Y., Liu, C. W., \& Zhao, S. L. (2014). $\mathrm{Fe}_{3} \mathrm{O}_{4} @$ aionic liquid@methyl orange nanoparticles as a novel nano-adsorbent for magnetic solid-phase extraction of polycyclic aromatic hydrocarbons in environmental water samples. Talanta, 119, 341-347.

[28] Hu, Y. Q., Guo, T., Ye, X. S., Li, Q., Guo, M., Liu, H. N., \& Wu, Z. J. (2013). Dye adsorption by resins: Effect of ionic strength on hydrophobic and electrostatic interactions. Chemical Engineering Journal, 228, 392-397.

[29] Ho, T. D., Cole, W. T. S., Augusto, F., \& Anderson, J. L. (2013). Insight into the extraction mechanism of polymeric ionic liquid sorbent coatings in solid-phase microextraction. Journal of Chromatography A, 1298, 146-151.

[30] Soylak, M., Unsal, Y. E., Yilmaz, E., \& Tuzen, M. (2011). Determination of rhodamine B in soft drink, waste water and lipstick samples after solid phase extraction. Food and Chemical Toxicology, 49, 1796-1799.

[31] Li, X. W., Zhang, J. W., \& Lu, T. L. (2011). Comparison of random vibration responses between traditional model and coupled model for a road-rail fire fighting vehicle. International Journal of Vehicle Noise and Vibration, 3, 238252 .

[32] Zhang, Q., Cui, L. H., Myint, A., Lian, M., \& Liu, L. J. (2005) Sensitive determination of phenolic compounds using highperformance liquid chromatography with cerium (IV) rhodamine 6G-phenolic compound chemiluminescence detection. Journal of Chromatography A, 1095, 94-101. 